\title{
The role of television in institutionalization of human resources principles in Iranian general policies of administrative system
}

\author{
Javid Imani $^{a}$, Reza Najaf Beygi ${ }^{b^{*}}$, Areyan Gholiopour ${ }^{\mathrm{c}}$ and Ali Akbar Farhangi ${ }^{\mathrm{b}}$
}

${ }^{a}$ Ph.D. Student of Media Management Department, Science and Research Branch, Islamic Azad University, Tehran, Iran

${ }^{b}$ Full Prof. \& The Head of Government Management Department, Science and Research Branch, Islamic Azad University, Tehran, Iran ${ }^{c}$ Associate Prof of Government Management Department, University of Tehran, Iran

\section{CH R O N I C L E}

\section{Article history:}

Received October 28, 2013

Received in revised format

25 November 2013

Accepted 19 January 2014

Available online

January 212014

Keywords:

Human resources

Institutionalization

Iran

Television

The general policies of

administrative system

\begin{abstract}
A B S T R A C T
"Iranian general policies of administrative system" is the mediator between the Islamic Republic of Iran vision in 2025 horizon and the practical field for establishing executive policies and laws, which is notified in 26 sections. This research aims to study the effects of television on institutionalization of six items of human resources principles in Iranian general policies of administrative system including human dignity, organizational justice, meritocracy, knowledge-basis, giving services in the deprived regions and honoring the retired. Research society consists of the management pundits familiar with media concepts. According to Grounded Theory and snowball sampling, 32 experts were interviewed and the institutionalization of human resources principles in Iranian general policies of administrative system model by television was extracted. The model discloses there has not been optimal utilization of television capacities for expressing the human resources principles in Iranian general policies of administrative system, but it is possible to use the capacity of television in planning and implementing these general policies. Considering the infrastructure and using appropriate strategies, television as the most influential mass media can be used in the axial issue, that is, the institutionalization of human resources principles in Iranian general policies of administrative system. It is crucial to notice the role of intervening factors in this area.
\end{abstract}

(c) 2014 Growing Science Ltd. All rights reserved.

\section{Introduction}

During the new millennium where "information" and "communication" are considered as the primary sources of "management", the media possess special characteristics. The duality of media, information and communication and their confluence with management and the direct and indirect role of medias in forming the social norms and institutional and individual values make a new and important equation in the current speedy world which is certainly on administrative system management. If the general policies of administrative system are considered as dynamism and stability of norms and values, it is possible to talk about the impacts of medias. In addition we can talk about television as the most pervasive media in administrative system regarding the direct effect *Corresponding author.

E-mail addresses: govmanagement@srbiau.ac.ir (R. Najaf Beygi) 
of "information" and "communication" and the hidden or obvious impact of "media" in formation and evolution of values and norms. If this relation is defined in a specific model framework, it can cause the flourish and dynamism of both media and administrative system.

Programming is the essence of management and since management is for achieving a goal, the essence and the heart of a program is nothing but the target and targeting (Koontz \& O'donnell, 1955; Schermerhorn, 1996). Thus, the Islamic Republic of Iran vision in 2025 announced by the supreme leader in June $13^{\text {th }}, 2003$ to the Triple Forces requires a developed country with first rate economical, scientific and technological position in the region, accompanied by Islamic and revolutionary identity and also inspiring in the Islamic world with high level interaction in international relations. Achieving this vision strongly depends on short-term goals, guidelines and general policies in all areas of political, economic, sociological, cultural and administrative system of society. Therefore, the revolution leader in April 20 ${ }^{\text {th }}, 2010$, imparted the "General policies of administrative system". These policies are organized in 26 sections (The supreme leader, 2010:9205) where six sections of which deals directly with the management of human resources including human dignity, organizational justice, meritocracy, knowledge-basis, giving services in deprived regions and honoring the retired. In order to implement the above policies, it is necessary to centralize the programmers' expected characteristics and behaviors in the administrative system and beyond that is to institutionalize these behaviors and characteristics in human resources of the administrative system of the country. Television, on the other hand, is a mass media, which influences all receptive powers of human including wisdom, delusion and imagination. Thus, one of the distinctive features of TV is its quality and attractiveness. Mass media usually brings about changes in the culture of society in the forms of artistic meaning, symbolic shapes, the meaning of fashion, behaviors, life styles and norms. At present, media is turned into the dominant source for definitions and formation of "social reality" for people (Farhangi \& Roshandel, 2005: 56). The mass media, specially the TV form the social realities by having impact on cognitive, normal and regulatory frameworks of society. Hence, the most timportan characteristic of an institutionalized feature is, indeed, its social reality (Roshandel, 2008:2).

In summary, to apply the imparted general policies of the administrative system, it is indispensable to institutionalize some characteristics in human resources of the administrative system. On the other hand, the mass media, especially television, is the most important factor in institutionalizing the behaviors in society. Therefore, the research question deals with the role of television as the most significant mass media in the country in institutionalization of human resources principals of general policies of the Iranian administrative system.

\subsection{The perspective and general policy}

The comprehensive model is the strategic management accepted by most scientists and researchers of strategic sciences. This model is illustrated in Fig. 1. Mission statement or the duty of the organization is the document that distinguishes one organization from others. In fact, the mission statement is the determiner of the organization status quo and its existential philosophy. The strategic manager in writing the mission statement is looking for answers to the following questions that "what we are?" and "what we are doing?" The values statement is, in fact, the do's and don'ts in the organization. The ideological frameworks and values of every organization make the associated cultural infrastructure and considering the fact that culture is the only factor, if compatible and supportive of the guideline, guarantees the long-run success of the organization. Therefore, it is important to take heed to the values of the organization and to codify the value statement for every group and organization, at the beginning of planning the guideline. Thus, the Islamic Republic of Iran constitution is the mission statement and values statement of the Islamic Republic of Iran. 


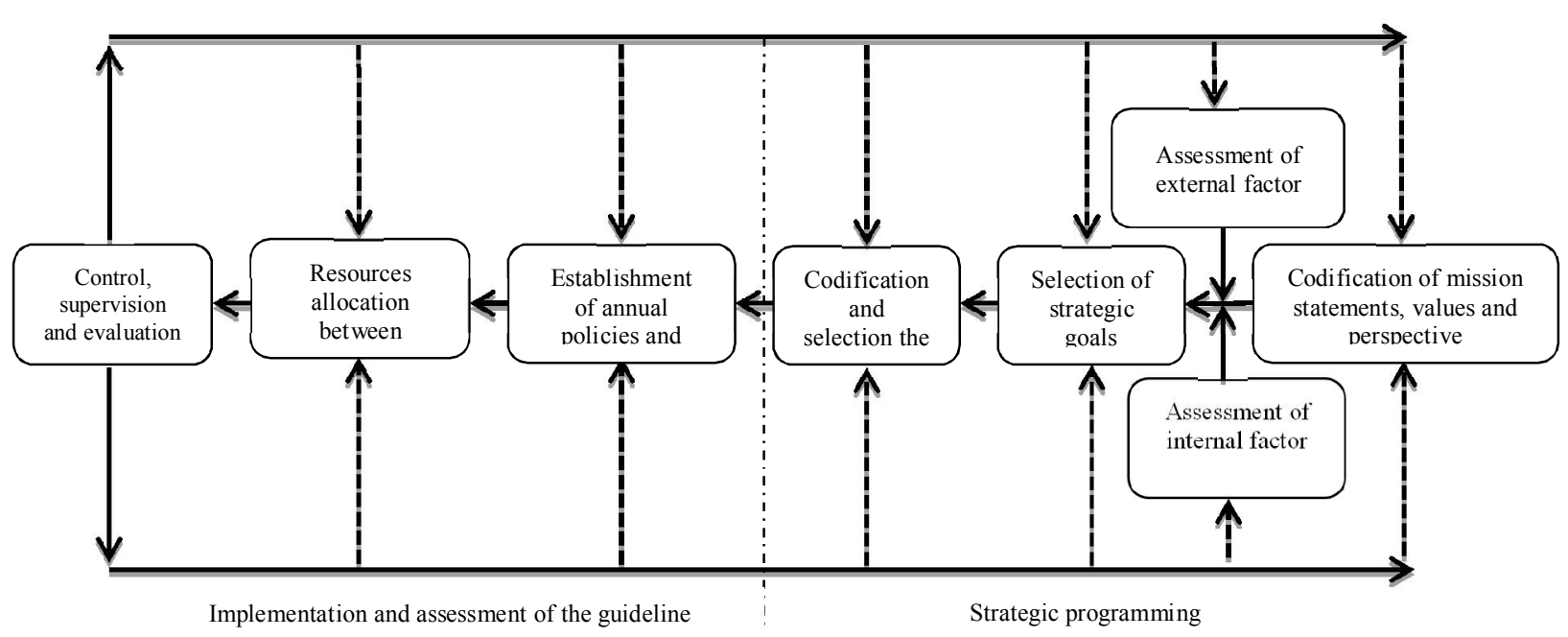

Fig. 1. Comprehensive model of strategic management (Freeman, 2010:33)

The perspective indicates the insight and foresight based on the picture and imagination of the future. The perspective in leader texture and organization is defined as an ideal, desirable and general state of the future of the organization (Kouzes \& Ponser, 1987: 227), which is a kind of mental picture of the desirable and possible future that can be vague like a dream or exact like the target statement (Nanus \& Bennis, 1985: 72). Therefore, the 20-year vision is, in fact, the perspective statement of the Islamic Republic of Iran. The product of strategic programming, after studying processes of internal and external factors and evaluation of options, is the major guidelines of organization, which are now ready to enter the implementation phase. These guidelines make the bed and direction for all practical plans decisions, which lead the organization to its ideal destination. These major guidelines are codified and imparted by the superb management of the system and the scholars' consultation. Next step is taken by the relevant organization and ministries, as intermediate managers of the Islamic Republic system, which have made the system prepared for implementing and performing the major guidelines or the general policies of the system (Jahadi, 2012:1).

\subsection{Institution and Institutionalization}

Institution is deduced as a concept of place or material which indicates to making a special place for a special activity or for a specific purpose or meet a special need and also indicates the beliefs, values, norms and regulations (Gholipour, 2006: 14).Management culture defines institutionalizing steady regulations and a criterion for social behaviors. Selznic describes iinstitutionalization as the establishment of meta-technical-equipment values in the current task, that is, the organic growth process that adapts with the domestic groups' efforts and extrinsic society values (Iravani, 2002: 69). Institutionalization, in a systematic and comprehensive definition, is a two-phase process: 1.Absorbing and getting the cultural values from the environment. 2. Accepting and structuralizing those values in order to establish, stabilize, transfer and continue them (Greenwood \& Hinings, 1996: 102). Therefore, institutionalization provides the basis and conditions, which leads to stability, consistency, permanency and pervasion of optimum behavior (Jelinek, 1979). An institutional concept should have the three features of consistency, pervasion and socializing reality. Approaching the social reality has got three factors and forces as follows,

1-Regulatory factors: terms and conditions in order to import meaning to the structures.

2-Normal factors: norms and values to import meaning to behaviors.

3-Cognitive factors: beliefs to impart meaning to both behaviors and structures (Gholipour, 2004: 21). 


\subsection{Mass Media and Institutionalization}

Mass media has a significant role in forming and pervading of social reality construction (Farhangi, 1996: 22). The mass media strongly touches the social reality construction through prevails the concepts in everyday life. They influence all individual and social aspects and determining role in formation of beliefs, perspectives and attitudes of society members and are known as a crucial source for advertising and distributing social values. The today media-bound lifestyle forms the human experience by producing images and models of reality, which are replacing the "reality" itself. These media only reflect some models of reality and make a mental picture for us (Baudrillard, 1990: 74). Based on the media-connection hypothesis and formation of social reality, the mental social reality formation degree of an individual is related to their direct experience in different phenomena, and as the result is related to the media dependence with providing information in these phenomena (BallRokeach \& DeFleur, 1976).

\section{Material and methods}

The research society, management pundits with media concepts, and media pundits are all familiar with management concepts. In order to do this research on the basis of Grounded Theory, the snowball sampling was used and 32 experts were interviewed. Then, the data were coded and extracted and a number of 18 issues in the form of 67 concepts were identified and then their characteristics and different aspects were made clear. According to the type of issue from the viewpoint of centrality, intervening conditions, infrastructure, guidelines and outcomes, the institutionalized model of general policies of the administrative system in the area of human resources by television was extracted.

In order to achieve the Grounded Theory for the role of television in institutionalizing human resources principles in general policies of the administrative system, the data were analyzed in open, axial and optional encoding stages. The data gathered through interviews were closely studied, analyzed and evaluated in open encoding and similar data received appropriated concepts. For example, the researcher analyzed the following quotation and extracted the concepts of "Administrative system trust to television" and "Television trust to the administrative system".

"If administrative system accepts that television enjoys great capacities and capabilities and also accepts it as a presupposition, it will be feasible to discuss which messages can be offered including the traffic culture, reforming the organizational culture and managers' attitudes. It is important that the custodians of the administrative system are aware well enough about different kinds of medium televisions. In addition, they need to invite the media organization for policy making in production of educational programs in administrative system. On the other hand, television managers should believe that presenting of the content by administrative system experts media and forming the content in media frameworks by TV programmers, producers and directors, are necessary in long-run culture-building programs."

In the above quotation, the researcher has extracted label of the administrative system to television by the notion of acceptable of television capacity by the administrative system custodians. Referring to this notion has also existed in other quotations that the researcher has extracted data analysis. In the above quotation, the respondent has indicated to the necessity of the television managers' belief to cooperation with the administrative system experts in order to make long-run culture-building programs. According to these quotations, the researcher has extracted the label of television trust to the administrative system. In the meantime, this concept has also existed in other data and as the result; other concepts were extracted in a similar way. After analyzing the data, labeling the events and extracting the concepts, each of these concepts were compared with each other to identify the 
similarities and differences in order to form the issues. For instance, the researchers, by comparing the different concepts, realized that the notions of "administrative system trust to television" and "Television trust to the administrative system" indicate one thing: the institutionalization of human resources principles of general policies of the administrative system needs, in the very beginning, the administrative system custodians' trust to the television capabilities and television trust to the administrative system and its capabilities in television program making. Based on this notion, the researchers have extracted the concept of "The bilateral interaction between administrative system and television". This concept is in a higher level of the above concepts and covers the two previous concepts. Other issues are also extracted in this way. There were 19 issues and 67 concepts identified and extracted. In addition to concepts and issues' extraction, the characteristics and features of every issue were extracted based on the contents and respondents' views. As an instance, the television approach toward the policies of the administrative system, which consists of programming perspective, prioritizing view and practicality, the respondents indicated that television can have a permanent or temporary viewpoint in general policies programming. It is also important that television cost a prioritized look over these policies. Most importantly, television itself should apply these policies. Consequently, the researcher has figured out that television approach toward the general policies of the administrative system in case of programming enjoys a prioritizing and functional look and can be short-term or long-term, prioritized on non-prioritized and political agent or political spokesman, respectively.

In axial encoding, the issues resulted in encoding the issues divided into six groups including axial issue, causal conditions, intervening conditions, guidelines (action and reactions), and outcomes. Among the extracted issues, "Institutionalization of human resources principles of general policies in the administrative system" is considered as an axial one, and is located at the center of the model. The reason behind choosing this issue as a pivotal one can be its clear observance in almost every data.

In other words, most respondents have indicated that the institutionalization of human resources principles of general policies in the administrative system of Iran by television requires special mechanisms and differs from the current methods, which cannot lead to the successful institutionalization of the general policies of the administrative system. Hence, this issue can be centralized with other issues. The selected label for the pivotal issue is also abstract and in the meanwhile enjoys comprehensiveness. Among other issues, television functions, the bilateral interaction between television and the administrative system, and television capacity are considered as the casual conditions. That is, Institutionalization of human resources principles of the general policies of the administrative system depends on how the television function are. In addition, it depends whether the bilateral interaction between television and administrative system exist, and television contains the capacity, maturity and capacity of doing such a task. Television approach to the general policies of the administrative system, audience centralization and the alignment of the administrative system function with the general policies of the system are introduced as the basis for institutionalization of the general policies of the administrative system. In other words, a set of conditions in which the action and reaction guidelines in institutionalization of human resources in the general policies of the administrative system is set by television. Issues determining television guidelines apply SWOT matrix, designing the administrative system programming model, and institutionalization of the administrative system programming model as the general guidelines for institutionalization of the human resources of the general policies of the administrative system of Iran. In other words, human resources institutionalization of the administrative system general policies is accomplished through determining the media guidelines, designing the administrative system programming model, and institutionalization of the administrative system programming model. Society conformity level, sustainability of the existing administrative system and television approach are considered as the intervening conditions, because they can facilitate the institutionalization of human resources in administrative system programming process through television. Eventually, human dignity, organizational justice, meritocracy, knowledge-basis, giving 
services in deprived regions and reforming the look toward the retired are expressed and the results and outcome of institutionalization of the human resources principles in the general principles of the administrative system. According to these explanations, the axial encoding model can be illustrated as in Fig. 2.

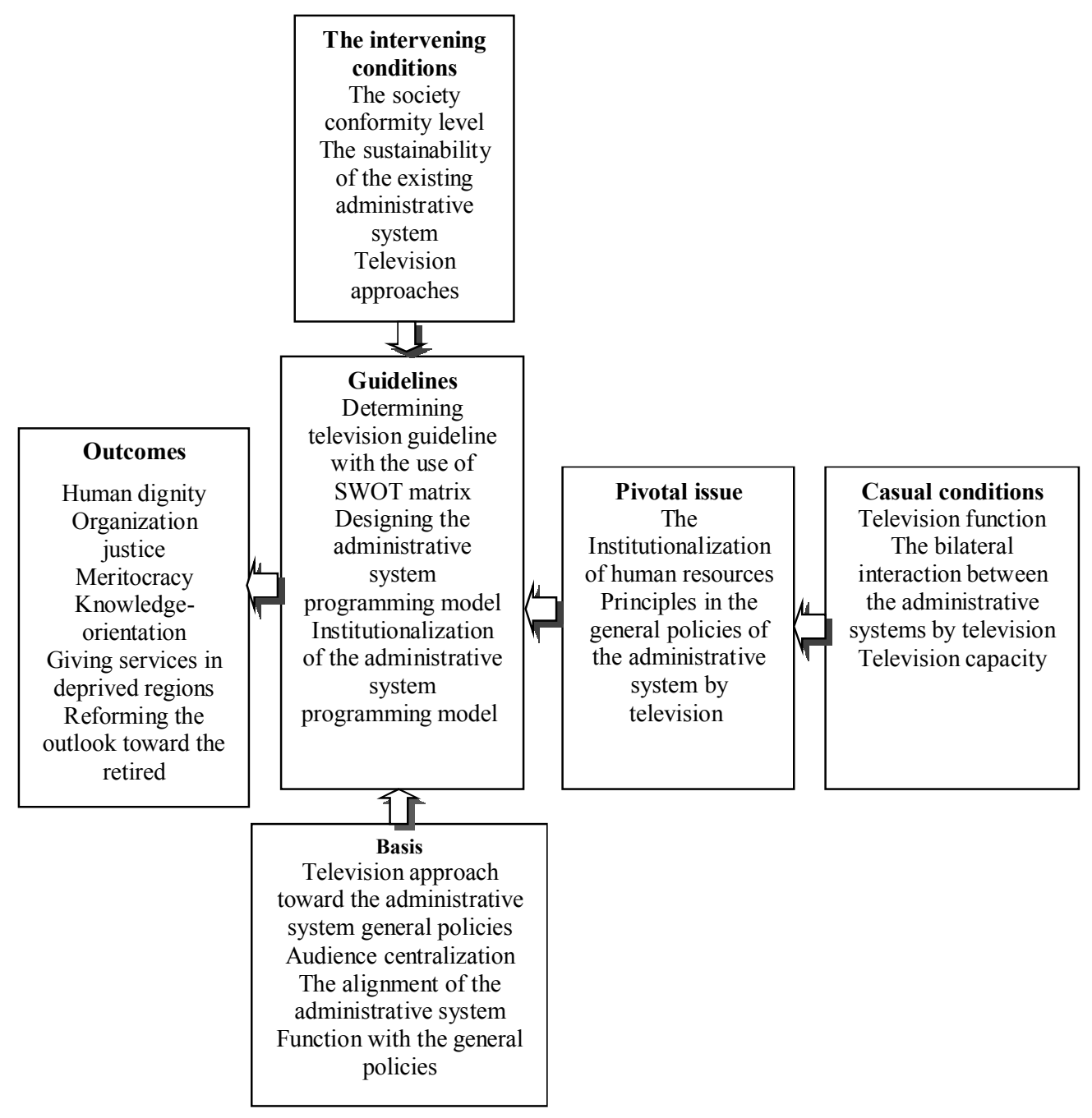

Fig. 2. The axial encoding model: The Institutionalization of human resource principles in the general policies of the administrative system

Optional encoding is the main stage in the Grounded Theory, which presents the hypothesis based on the results of the open and axial encoding. Optional encoding is the integrating, improving and refining process of the issues, in that, the researcher for preparing and forming a hypothesis makes a special harmony and setting among the issues.

At this level, it is attempted to put the issues together around the pivotal issue as the main concept to make a systematic order between these concepts and issues. Data analysis shows that the television function in the area of institutionalization principles in the general policies of the administrative system can only be desirable and appropriate if it depends on its own capacity and media functions. It also has to make bilateral interaction with the administrative system and uses appropriate guidelines to institutionalize the human dignity, organizational justice, meritocracy, knowledge-basis, giving services in deprived regions and reforming the outlook to the retired in the administrative system. The results of the optional encoding lead to the following extracted model shown in Fig. 3. 


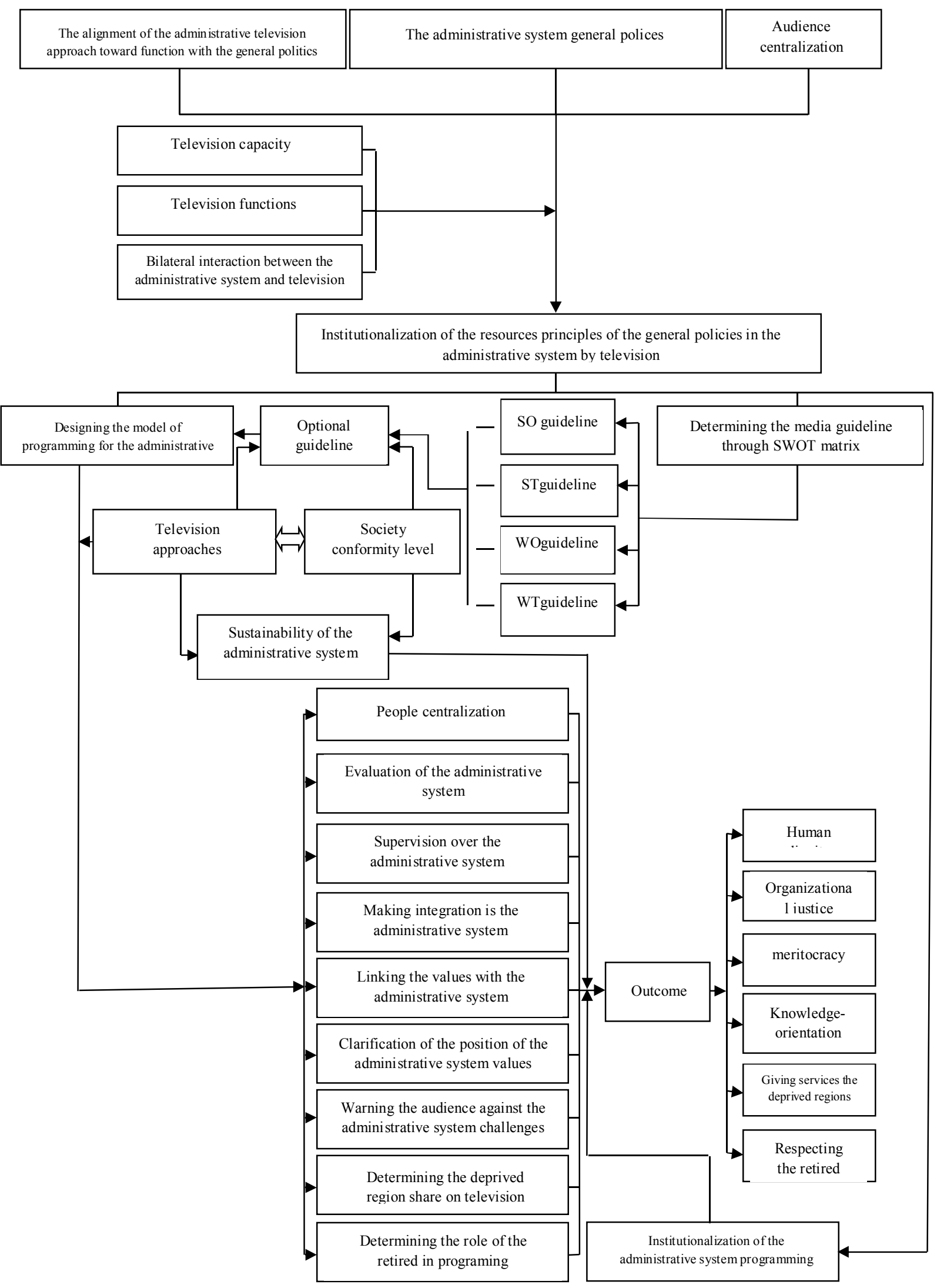

Fig. 3. The model of institutionalization of the human resources principles by television in the general policies of administrative system 


\section{Results}

1. Television has sporadically been used to introduce the administrative system favorite features to the society in past, but this introduction can be systematic. In order to use the television capacity in introduction of these features, the content of the programs which are made about the administrative system should be able to familiarize the viewers with given policies or enhances the audience understanding.

2. In the past, television did not have a special role in arrangement and implementation of legal laws and regulations and punishments of the administrative system, but it can have some role in this area. Therefore, adjusting conformity of television programs with the general policies of the administrative system for institutionalizing these policies in the area of human resources is necessary. In other words, the administrative system TV programs must make the audience familiar with administrative system terms and conditions arising from the general policies or enhance their understanding, and transfer the existing problems to law makers in order to make or reform laws.

3. In the past, television had a sporadic role in making the values of the administrative system, but this role can be more effective. Thus, the content of TV programs must be in harmony with the defined norms of the administrative system.

4. In the past, the role of television in changing the considered characteristics with the administrative system law makers to a social reality was less significant, which TV can play an important role in executing these characteristics. In order to achieve this goal, it is necessary that content of TV programs be compatible and harmonious with the content of the general policies, so that the content of these programs is introduced as a pattern for the society.

5. In the past, the capacity of TV was not significantly used to make a kind of culture in which human dignity was noticed, but this capacity can be used to make this kind of culture in organizations and society. Therefore, human dignity must be the most indispensable and prioritized concept in human resources management for TV managers in program making, because the concepts of "Organizational justice", "Meritocracy", "Knowledge-basis", "Giving services in deprived regions" and "Reforming the retired" are all subdivisions of "Human dignity". If the concept of human dignity receives the utmost importance in the programs related to the general policies of the administrative system, there can be the hope that other concepts gradually get institutionalized in society and administrative system. It is not meant that other concepts should be forgotten, but considering the media restrictions and avoid giving too many programs to the audience, taking heed to the concept of human dignity is of utmost priority. As the concept of human dignity is taken from the Islamic practices, the formation of a kind of organizational culture, based on Islamic value in organizations, and a dignity-based viewpoint toward the personnel in organizations can be observed.

6. Television has sporadically been used to spread the organizational justice, but it can directly be used to do so. This task can be accomplished by expressing the concept of justice-seeking in organizations, studying the individual and organizational share in justice centralization and strengthening the mental and visual aspects of justice through informing the audience and making them sensitive.

7. Television does not have any significant role in this area that individuals show their capabilities in organizations, and, on the other hand, organizations need to be committed to prove their meritocracy policies, while TV can have a noticeable role in this field. Thorough an exact explanation of the ability and inclination, which are two wings of competence, showing the competence people, and emphasizing on competent personnel in today's economic world and TV can encourage the personnel to be effective. 
8. TV has sporadically been used to make the inclination towards improving the knowledge and skill in organizations, but it can have an effective role in this subject. Knowledge orientation as one of the characteristics of knowledge-bound means whether or not TV can define the difference between information and knowledge. It can also define the importance of utilizing the knowledge in changeable environments for the audience. It can increase the number of knowledge-oriented programs on TV, regarding the knowledge-oriented competence and skill along with commitment. As a result, the gradual institutionalization of extreme degree-orientation in society can be expected. On the other hand, skill-orientation, as the second characteristic of knowledge-bound will be the consequence of the skill role versus pure knowledge, an increase in the share of skill-bound programs, education of organizational skills like negotiation, problem solving and not being biased on titters on TV.

9. In past, TV had a twofold attitude toward encouraging the employees to work in the deprived regions. In other words, it sometimes encourages the employees to work in the deprived regions and sometimes highlights the shortcoming of these regions, which consequently discourages the employees to work in these regions, or at least, it could be said that TV is not encouraging; while TV can have an important role in this subject. If TV efficiently does its given responsibilities, based on the program making model, it can be encouraging for working in the deprived region from to perspectives of "Encouraging factors" and "Employees". In encouraging factor discussion, the emphasis of TV is on the spiritual values as well as informing about the financial motives, which eventually results in more demand for work in these areas. On the other hand, regarding the importance of empowerment of the native employees in the deprived regions to develop these regions, the true function of $\mathrm{TV}$ can encourage the native employees to develop their region, by absorbing non-native technicians or transferring non-native employees in the expertise or skills, which are actually not available in these regions.

10. In the areas of providing the livelihood, preserving the honor and transferring the experience of the retired, TV has had some role, but it should have a pivotal role. If TV, as a bridge between the young generation and the retired, while respecting the latter group, reflects their livelihood concerns and uses their experiences in educational programs, the lookout culture toward the retired as the pioneer group and transferor of experience will be institutionalization in society, and the retired will be considered as an asset. In addition, the duty of law makers in ratifying the gradual retirement law in the administrative system to prevent the mental vacuum and gradual transferring of their experiences must not be ignored.

11. Audience centralization means the necessity to audience research, consistency of the program with the audience and media literacy of the audience. Audience centralization is one of the basic conditions for institutionalization of the human resources principles of the general policies in the administrative system and it has got direct relation with television success in achieving this goal.

12. The type of television approach toward the general policies of the administrative system is the second basic condition for institutionalizing these policies. In other words, the program making outlook (long-run or short-run), prioritizing outlook in program making (prioritized or nonprioritized), and pragmatism (an agent of policies or solely a speaker of the policies) is efficient in institutionalizing the general policies.

13. The institutionalization of the human resources principles of the general policies in the administrative system can only be successful when the administrative system function is aligned with the general policies or the third basic condition for institutionalizing these policies is the alignment of the administrative system function with the general policies. On the other hand, the managers and the personnel orientation toward these policies should be aligned. 
14. The institutionalization of the human resources of general policies in the administrative system requires the TV capacity in powerful program making and processing technical channels. In this case, the concept of being private, independent from government and management and structural evolution are necessary.

15. TV can be successful in institutionalizing the human resources principles of general policies of administrative system, if it pays attention to all its function, not only some of them.

16. The bilateral interaction between the administrative system and television for institutionalizing the human resources principles in general policies of the administrative system is necessary.

17.The background of using TV for institutionalizing the human resources principles in general policies of the administrative system is determining the media guideline considering the internal and external conditions and by utilizing SWOT matrix.

18. Based on the optional guideline of $\mathrm{TV}$, it is necessary to design a model for the administrative system program making in order to institutionalize the human resources principles of the general policies in administrative system. This model should be based on people-orientation, studying the administrative system, supervision over the administrative system, giving consistency to the administrative system, integrating the value with administrative system, noticing the administrative system values, warning the audience against the administrative system challenges, determining the share of the deprived regions in TV and determining the role of the retired in program making.

19. In order to institutionalize the human resources principles in the general policies of the administrative system, it is necessary to plan a program making model on the basis of the media guideline from the two perspectives of legitimacy and stability.

20. The society conformity with the general policies includes the cultural conformity, cognitive conformity, normal conformity and adjusting conformity of the intervening factor in institutionalizing the human resources principles of the general policies of the administrative system. In other words, to what extent should general culture of society, beliefs, values and existing regulation be in conformity with the general policies of the administrative system to have a positive role in institutionalizing these principles?

21. The consistency of the existing administrative system is another intervening factor in institutionalizing the general policies of human resources of the administrative system.

22. Another intervening factor in institutionalizing the human resources principles of general policies in the administrative system is television approach. There are five intervening approaches in the process of institutionalizing these policies including the security, political, professional, content and evolutionary approaches.

23. If other components of the model have correct functions, the institutionalization of human dignity, organizational justices, meritocracy, knowledge-centralization, giving services in the

deprived regions and honoring the retired will take place. The side effects of the two factors of the existing administrative system consistency and institutionalizing the programming model of the administrative system should not be ignored.

\section{Discussion}

\subsection{Comparing the Research with Institutionalizing Research}

Boltanski (1987) is one of the researchers who studied the role of the popular French press in conceptualizing and institutionalizing the idea of modern management in that country for the first time. According to his research, the papers and other popular press have the most impact and role in 
forming and shaping such a language and literature (Boltanski, 1987; Djeli, 1998). As it can be noticed, Boltanski believes that his considered media i.e. the press has got significant role in creating and institutionalizing of the modern management talks. At the present study, the basic principles of institutionalization namely the cognitive principle, normal principle and adjusting principle are indicated. In the axial issue, it is only possible to utilize the television capacity for institutionalization of the human resources principles of the general policies in the administrative system where the content of television programs are matched with the general policies. In terms of the cognitive viewpoint, we should assist the audience to familiarize with the policies. In terms of the normal viewpoint, we should spread the dominant values of the policies and from the adjusting viewpoint we should explain the rules and regulations in the administrative system.

Mazza and Alvarez, in a similar study, investigated the growing role of Italian newspapers in forming professional management models and using role of popular media is changed from spreading and transferring the solely ready-made management ideas to forming and shaping these ideas and legitimatizing the converted management theories and actions (Mazza \& Alvarez, 2000: 567). If, in Mazza and Alvarez study, the news and educational function of television is the role of popular media in emergence of management theories and actions and the reasoning function of television in institutionalization management is legitimatizing, there will be a common point in which the management and media pundits take special heed to the television functions. There is a delicate notion in the current study which emphasizes on the fact that excessive attention of the media managers to a specific function of television such as news or entertainment function will cause negligence of other functions. Therefore, it will lead to forgetfulness or rejection of television function by media managers and other parts of society. In Mazza and Alvarez research, the unilateral role of media in legitimatizing the knowledge and management actions is emphasized. There is another point in this study which shows its deeper look over the concept of institutionalization than the above mentioned study, and that is the necessity of bilateral interaction between the administrative system and television in order to institutionalize the human resources principles in the general policies of the administrative system.

In another research, Frenkel (2005) studied the role of mass media over the institutionalization of professional management talks and utilization. Depending on systematic analysis on a nonprofessional newspaper (non-technical), he suggests that the mass media are the means in which professional thoughts and ideas are flourished and eventually accepted by people without any questions. What makes difference between this study and Frenkel's research is the different type of look over the audience. Frenkel claims that the audiences unquestionably accept the professional thoughts and ideas conveyed by the media, which is the sign of the media power or audience inactivity. However, this study focuses on active audience, which is a kind of audience who strongly react to the television approaches.

A number of five television approaches identified as intervening factors in this study can be influential in accepting or rejecting television by the audience, and, as the result, they can influence on the general policies of the administrative system. Today's television audience understands the role of securing the society by television and it reacts toward the subjective approach against the national approach and differentiates the professional television program from the non-professional ones. In addition, when unintentional content of programs opposes the defined norms and beliefs of television, the exactness of program-makers will be under question, and they will complain when television does not ask for logical changes in the existing organizations and systems. Therefore, at the present situation, it is not possible to consider the media as active and the audience as inactive to accept everything on television. This notion does not reject the media power in institutionalization, but states the fact that utilizing the television capacity as the most popular mass media requires considering all necessary conditions such as infrastructure, causal, guideline and intervening conditions. 


\section{Conclusions}

According to the upstream documents of defining the production goals, axes, and priorities, providing and spreading the programming groups in television, the television capacity in past was not fully used in planning the human resources principles of the general policies of the administrative system, but it is feasible to use this capacity to plan and implement these policies. Television as the most efficacious mass media, considering the infrastructure and causal condition and by using appropriate guidelines, can be used to achieve the pivotal issue which, in fact, is the institutionalization of the

human resources principles of the general policies of the administrative system. The role of intervening factors should not be neglected, though.

\section{References}

Baudrillard, J. (1990). Mass media culture. Revenge of the crystal: Selected writings on the modern object and its destiny, 1968-1983.

Ball-Rokeach, S. J., \& DeFleur, M. L. (1976). A dependency model of mass-media effects. Communication research, 3(1), 3-21.

Bennis, W. G., \& Nanus, B. (2003). Leaders: Strategies for taking charge. Harper Collins.

Bolanski, L. (1987). The Making of Cadres in French Society. Cambridge University Press.

Freeman, R. E. (2010). Strategic management: A stakeholder approach. Cambridge University Press.

Farhangi, A.A. (1996). Mass media and its role in social reality construction. Journal of Management Knowledge, 29-30.

Farhangi, A.A., RoshandelArbatani, T., \& Bargi, M. (2002). An overview over theoretical basis of media organizations' management. Journal of Management Knowledge, 66.

Frenkel, M. (2005). Communicating management: The role of the mass media in the institutionalization of professional management and productivity discourse in Israel. Scandinavian Journal of Management, 21(2), 137-157.

Gholipour, A. (2006). Institutions and Organizations: Institutionalized ecology of organizations. Tehran: Samt Press.

Greenwood, R., \& Hinings, C. R. (1996). Understanding radical organizational change: Bringing together the old and the new institutionalism. Academy of management review, 21(4), 1022-1054.

Iravani, M.J.(2002). An overview on the institutionalized Theory. Tehran: Siasat Press.

Jahadi (Retrieved 2012). "The position of the general policies in the strategic management system", from http://www.jahadi.ir

Jelinek, M. (1979). Institutionalizing innovation: A study of organizational learning systems. New York: Praeger.

Koontz, H., \& O'donnell, C. (1955). Principles of Management: An Analysis of Managerial Functions.

Kouzes, J. M., \& Posner, B. Z. (1987). The leadership challenge. San Francisco: Jossey Bass.

Mazza, C., \& Alvarez, J. L. (2000). Haute couture and prêt-à-porter: the popular press and the diffusion of management practices. Organization Studies, 21(3), 567-588.

RoshandelArbatani, T. (2008). Designing and establishing a model for institutionalizing the strategic program for society in public opinion through Mass media: the 20year vision (Iran,2026). The media management doctoral thesis, Tehran University: Management Department.

Schermerhorn, J. R. (1996). Management and organizational behavior essentials. John Wiley. 